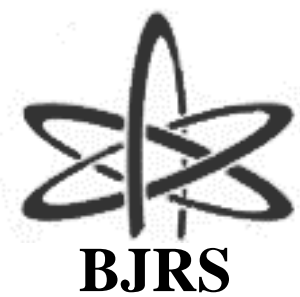

BRAZILIAN JOURNAL

$\mathrm{OF}$

RADIATION SCIENCES

08-02 (2020) 01-12



\title{
Concentration and distribution of oil in the reservoir mineral Dolomite studied by neutron tomography
}

\author{
Pugliesi R., Stanojev Pereira M. A., Andrade M. L. \\ Instituto de Pesquisas Energéticas e Nucleares IPEN-CNEN/SP.
}

Av. Prof. Lineu Prestes 2242, Butantã, Cidade Universitária

CEP 05508 000, São Paulo - SP, Brasil

pugliesi@ipen.br

\begin{abstract}
Neutron Tomography - NT is a non-destructive technique, ideal for imaging hydrogen-rich substances even when wrapped up by thick rock layers. In the present study, the NT was employed for investigating the oil concentration and distribution in the mineral Dolomite, a natural oil reservoir. Two types of Dolomite samples, one of which dry, and the second one in oil-saturated were prepared. The applied oil was EMCAplus® ${ }^{\circledR} 70$ usually employed in permeability experiments to reproduce conditions of natural oil reservoirs. Three small fragments of the dry sample and three of the oil sample were inspected by NT and the comparison between the obtained results enabled, to distinguish several regions in which the oil is stored, to indicate that the oil is dispersed throughout the volume of the samples, and to quantify the storage concentration. The obtained data for oil concentration, for the three fragments, were compared to each other and to the one obtained by the conventional gravimetric technique, and they agreed within their uncertainties, demonstrating the viability of the NT technique to inspect, either in a qualitative as in a quantitative level, this oil reservoir mineral.
\end{abstract}

Keywords: Petroleum prospection; Oil reservoir minerals; Neutron tomography. 


\section{INTRODUCTION}

Unlike X-rays tomography technique, the neutron-matter interaction processes attribute unique characteristics to the NT technique, from which it is possible to distinguish small amounts of hydrogen-rich substances like water, oil, adhesives and others, even wrapped up by thick material layers like, some metals and rocks. Thus, often the information obtained by NT and X-ray tomography are complementary to each other. Therefore, the NT technique is highly desirable in studying oil in mineral samples. Carbonate deposits are one of the main oil and gas reservoirs in the world's most relevant petroleum systems, Calcite and Dolomite are the main constituent minerals of carbonate rocks [1-10]. The objective of the present paper was investigating the distribution and concentration of the oil EMCAplus ${ }^{\circledR}$ 070, usually employed in permeability experiments to reproduce conditions of natural oil reservoirs [11], in Dolomite, using the NT facility of the Brazilian Institute for Nuclear Technology IPEN-CNEN/SP. The obtained images demonstrated the viability of the NT technique and of the present facility to investigate this natural oil reservoir mineral.

\section{EXPERIMENTAL}

The NT facility of IPEN-CNEN/SP, showed in the Fig. 1, is installed at the Beam-Hole \#14 of the 5MW pool type IEA-R1 Nuclear Research Reactor. Briefly, a tomography is obtained as follows: the sample is positioned in an automated rotating table for irradiation; the intensity of neutrons transmitted by the sample impinges a scintillator screen (NE-426) forming a two dimensional image of its internal structure; a mirror reflects this image to a video camera (Andor Ikon-M), which is captured and stored in a computer (DELL precision 5500 work station); after capturing the image, the sample is rotated $0.9^{0}$ and another image is captured, until completing $360^{\circ}$. The file with these 400 images is processed by the software "Octopus" generating the tomographs, and the 3D images are generated by the software "VG Studio" [12, 13]. The main characteristics of the facility are: neutron flux at irradiation position $8 \times 10^{6} \mathrm{n} \cdot \mathrm{s}^{-1} \cdot \mathrm{cm}^{-2}$; maximal 
spatial resolution $(205 \pm 24) \mu \mathrm{m}$; maximal beam diameter $16 \mathrm{~cm}$; time spent per tomography $400 \mathrm{~s}$ [14].

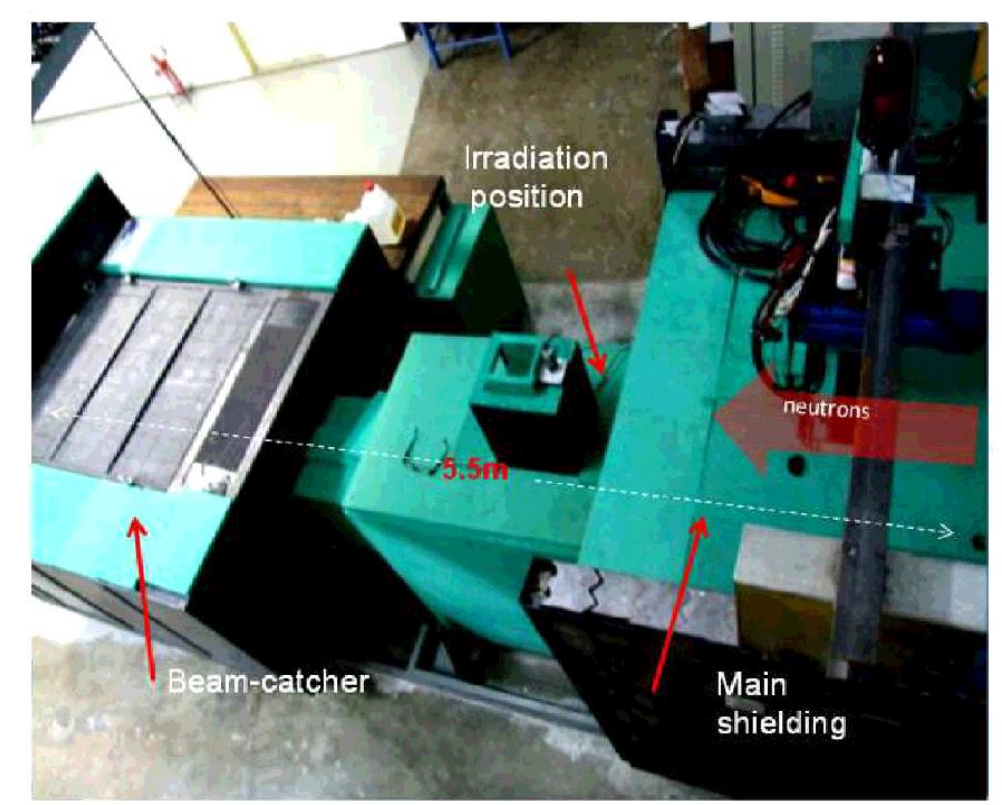

Figure 1: NT facility of the IPEN-CNEN/SP.

The sample is a Silurian Dolomite, a sedimentary rock composed primarily by the mineral Dolomite, with chemical composition $\mathrm{CaMg}\left(\mathrm{CO}_{3}\right)_{2}$, found in sedimentary basins worldwide. Its basic composition is dolomite $97.86 \%$, calcite $1.58 \%$, quartz $0.35 \%$, others $0.22 \%$ [15]. For the purpose of the present study, two samples were prepared. Firstly, both were kept for 24 hours in an oven at $60^{\circ} \mathrm{C}$, with relative humidity at $45 \%$, for drying. After that, one of the dried samples, Fig. 2a, was stored until the tomography is performed. The second sample in Fig 2b, was submitted to an oil saturation process, known as Flow-Through, in which the Dolomite is inserted in a core holder, and the oil is forced by pressure to penetrate into the sample [15]. The oil employed was the EMCAplus ${ }^{\circledR}$ 070, an industrial and laboratorial oil with viscosity, density and oleic phase similar to the hydrocarbon, usually used in permeability experiments to reproduce conditions of natural oil reservoirs [11]. After this process, this sample was kept immersed in oil at atmospheric 
pressure, until the tomography is performed. The two samples are cylinders $(\phi=39.2 \mathrm{~mm} ; \mathrm{h}=$ $53.8 \mathrm{~mm})$, with masses $\mathrm{m}(\mathrm{g})=150.27$, and $\mathrm{m}(\mathrm{g})=157.59$ for the dry and for the in-oil respectively.

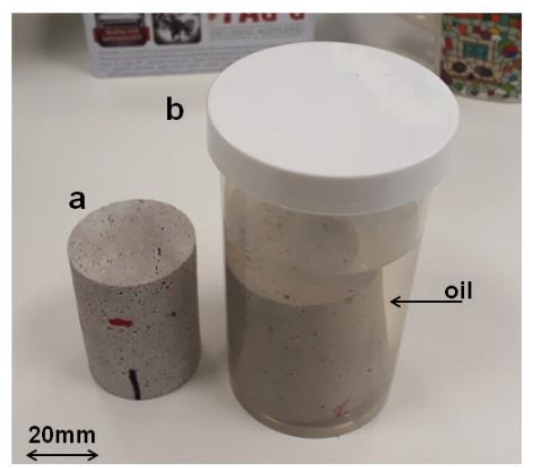

Figure 2: Dolomite samples: (a) dry; (b) in-oil.

In order to minimize the neutron multiple scattering in the samples to be inspected by NT, that would mask the resulting images, these samples were fragmented, and three samples of the dry, and three of the immersed in-oil, with masses showed in the Table 1, were selected [16].

Table 1: Masses of the inspected samples.

\begin{tabular}{cccc}
\hline Mass & sample 1 & sample 2 & sample 3 \\
\hline $\mathbf{M}(\mathbf{g})-$ dry & $7.97 \pm 0.02$ & $6.53 \pm 0.02$ & $3.85 \pm 0.02$ \\
\hline $\mathbf{M}(\mathbf{g})-$ in-oil & $6.18 \pm 0.02$ & $4.06 \pm 0.02$ & $6.00 \pm 0.02$ \\
\hline
\end{tabular}

\section{RESULTS AND DISCUSSION}

3.1. - Dry samples. The three dry samples were inspected by NT and from the obtained images, it was possible to discern (see Fig. 3c), three distinct ranges of neutron attenuation coefficients, differentiated by colors (red, yellow, green). The Figs. 3a, 3b and 3c show, one of the inspected samples, a 3D general view, and a 3D image sliced in two distinct viewing planes, respectively. Table 2 illustrates the quantitative results for the sample volume $\mathrm{V}\left(\mathrm{cm}^{3}\right)$ and for the volume 
fractions $\mathrm{Vf}(\%)$ corresponding to each measured attenuation coefficient range, varying from $\Sigma \mathrm{d}\left(\mathrm{cm}^{-1}\right) \leq 0.22$ (green) for the most transparent, to $0.29<\Sigma \mathrm{d}\left(\mathrm{cm}^{-1}\right) \leq 0.35$ (red) for the most attenuating region. Typically, attenuation coefficients vary from $\sim 0 \mathrm{~cm}^{-1}$ for absence of materials to $\sim 3.0 \mathrm{~cm}^{-1}$ for the highly attenuating materials [17]. These results, when compared to the image obtained by Scanning Electronic Microscope (S.E.M.), see Fig. 4, indicate that these ranges correspond to distinct porosities in the sample, which because of the spatial resolution limit of the present NT facility, are not discernible in the images.

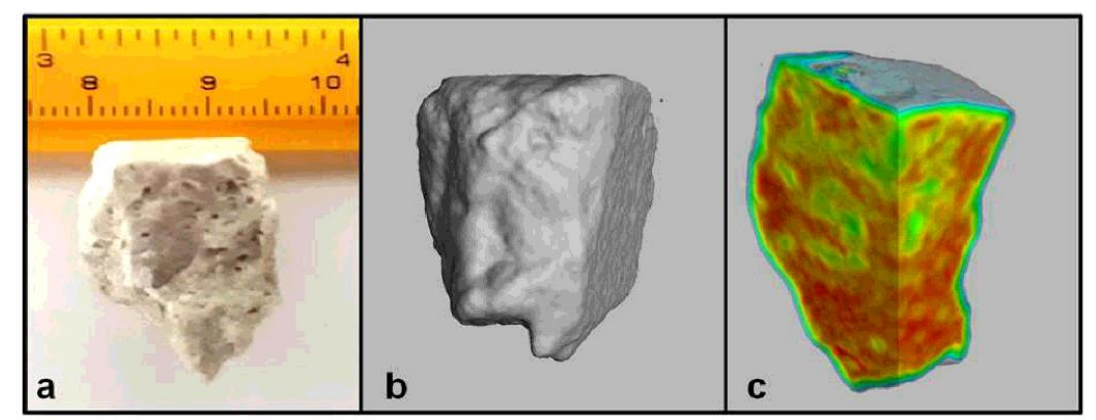

Figure 3: Dry sample: a) One of the inspected samples; b) 3D general view; c) 3D sliced image showing the three colored regions.

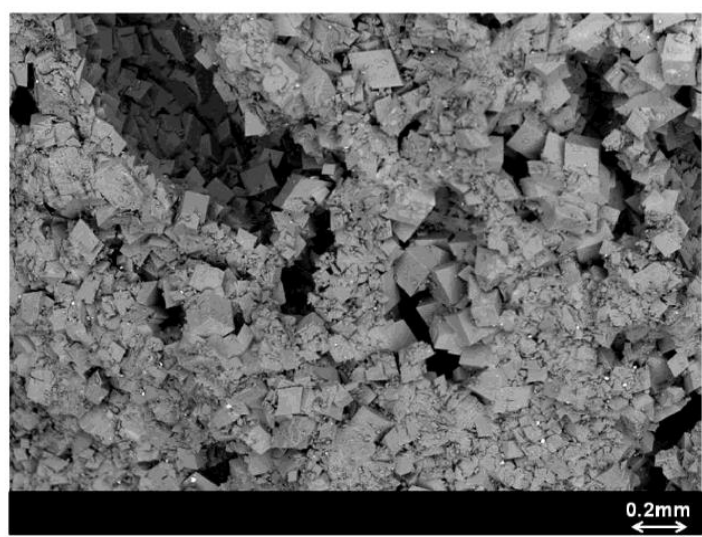

Figure 4: S.E.M. image (80x) for the dry sample. 
Table 2: Parameters evaluated from the tomographic images for the dry samples.

sample 1 sample 2 sample 3

\begin{tabular}{cccc}
\hline volume $\mathbf{V}\left(\mathbf{c m}^{\mathbf{3}}\right)$ & 3.526 & 2.743 & 1.614 \\
\hline Att. coef. $\Sigma \mathbf{d}\left(\mathbf{c m}^{-1}\right)$ & $\mathbf{V f}(\%)$ & $\mathbf{V f}(\%)$ & $\mathbf{V f}(\%)$ \\
\hline$\Sigma \mathrm{d} \leq 0.22$ (green) & 25 & 21 & 25 \\
\hline $0.22<\Sigma \mathrm{d} \leq 0.29$ (yellow) & 60 & 59 & 51 \\
\hline $0.29<\Sigma \mathrm{d} \leq 0.35$ (red) & 15 & 20 & 24 \\
\hline
\end{tabular}

3.2 - In-oil samples. The three in-oil samples were inspected by NT and from the obtained images, it was possible to discern (see Fig. 5c), four distinct ranges of neutron attenuation coefficients, differentiated by colors (red, yellow, green, light blue), in this case reflecting four distinguishable densities in which the oil is stored. The Figs. 5a, 5b and 5c show, one of the inspected samples, a 3D general view, and a 3D image sliced in two distinct viewing planes, respectively. Table 3 shows the quantitative results obtained for the sample volume $V\left(\mathrm{~cm}^{3}\right)$, and for the volume fractions $\mathrm{Vf}(\%)$ corresponding to each measured attenuation coefficient range, varying from $\Sigma \mathrm{o}\left(\mathrm{cm}^{-1}\right) \leq 0.57$ (light blue) the most transparent to $1.07<\Sigma \mathrm{o}\left(\mathrm{cm}^{-1}\right) \leq 1.4$ (red) the most attenuating region [17]. The selected colored region in Fig. 6, obtained by Scanning Electronic Microscope (S.E.M.) shows that the oil is distributed throughout the sample.

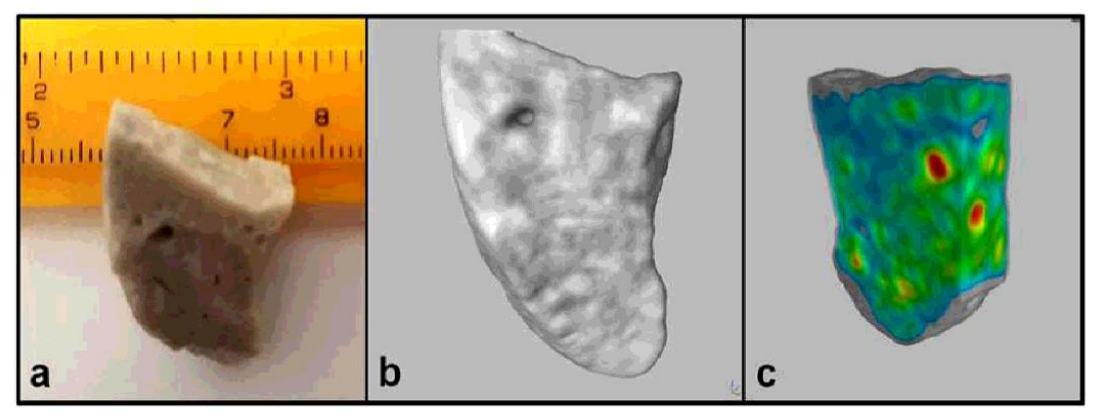

Figure 5: In-oil sample: a) One of the inspected samples; b) 3D general view; c) 3D sliced image showing the four colored regions. 
Table 3: Parameters evaluated from the tomographic images for the in-oil samples.

\begin{tabular}{|c|c|c|c|}
\hline $1 / / / / / / / / / / / / / / / / / / / / / / /$ & sample 1 & sample 2 & sample 3 \\
\hline volume $\mathrm{V}\left(\mathrm{cm}^{3}\right)$ & 2.232 & 1.535 & 2.209 \\
\hline Att. coef. $\Sigma o\left(\mathrm{~cm}^{-1}\right)$ & $\operatorname{Vf}(\%)$ & $\operatorname{Vf}(\%)$ & $\operatorname{Vf}(\%)$ \\
\hline$\Sigma o \leq 0.57$ (light blue) & 17 & 15 & 14 \\
\hline $0.57<\Sigma o \leq 0.83$ (green) & 74 & 62 & 74 \\
\hline $0.83<\Sigma o \leq 1.07$ (yellow) & 7 & 20 & 10 \\
\hline $1.07<\Sigma_{0} \leq 1.4(\mathrm{red})$ & 2 & 2 & 2 \\
\hline
\end{tabular}

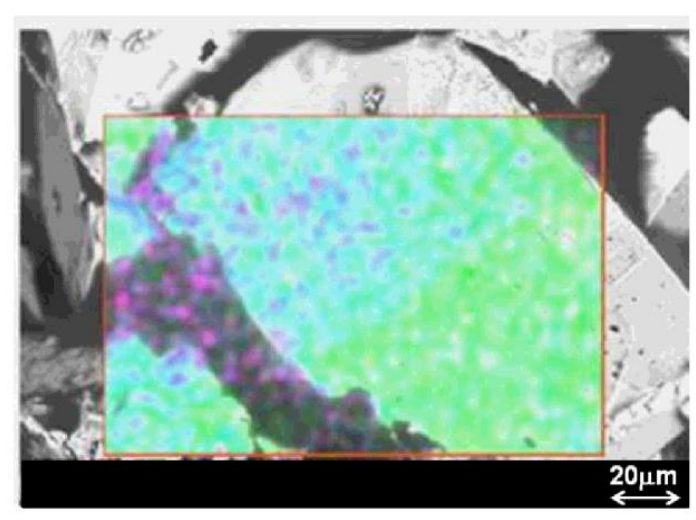

Figure 6: S.E.M. image (1000x) for the in-oil sample.

A very important parameter also evaluated in the present study, was the oil concentration in the studied samples, here defined by the ratio $\left(\mathrm{m}_{\mathrm{oil}} / \mathrm{M}\right)$ where $\mathrm{m}_{\mathrm{oil}}$ is the oil mass stored in a sample with mass M.

The oil mass - $\mathrm{m}_{\text {oil }}$ for each sample, was evaluated by (1)

$m_{o i l}=f \cdot \rho \cdot V$ 
where $\rho=0.82 \mathrm{~g} / \mathrm{cm}^{3}$ is the density of the pure EMCAplus ${ }^{\circledR} 070$ oil [11]; $\mathrm{V}\left(\mathrm{cm}^{3}\right)$ is the volume of each respective sample (Table 3), and "f" is the ratio between, the oil density within the samples and the pure oil density. This parameter was evaluated by expression (2), derived from the neutron transmission law by matter [16], and $\mathrm{f}=0.16 \pm 0.04$. The uncertainty in "f" was evaluated according the standard propagation rules, applied to (2) [18].

$\Sigma o_{(a v g)}=\Sigma d_{(a v g)}+f . \Sigma o i l_{(a v g)}$

where $\Sigma \mathrm{o}_{\text {(avg) }}\left(\mathrm{cm}^{-1}\right)=0.81 \pm 0.12$ is the average neutron attenuation coefficient measured throughout the volume of the in-oil samples; $\Sigma \mathrm{d}_{(\mathrm{avg})}\left(\mathrm{cm}^{-1}\right)=0.30 \pm 0.03$ is the average neutron attenuation coefficient measured throughout the volume of the dry samples; $\operatorname{Voil}_{(\mathrm{avg})}\left(\mathrm{cm}^{-1}\right)=$ $3.10 \pm 0.02$ is the average attenuation coefficient for the pure EMCAplus ${ }^{\circledR} 070$ oil. The uncertainties in $\Sigma \mathrm{o}_{(\text {avg) }}, \Sigma \mathrm{d}_{\text {(avg) }}$ and $\Sigma$ oil (avg) are the standard deviation of their respective means [18].

The obtained values for the oil concentration $\left(\mathrm{m}_{\mathrm{oi}} / \mathrm{M}\right)$ were $0.049 \pm 0.011,0.052 \pm 0.012$ and $0.050 \pm 0.012$ for the samples (1), (2) and (3) respectively, and they agreed within their uncertainties, demonstrating the reproducibility of the NT method. The uncertainties were evaluated according the standard propagation rules [18], taking the uncertainty in $\mathrm{V}\left(\mathrm{cm}^{3}\right) \sim 0$ [13]. Furthermore, these results also agreed with the one obtained by the conventional gravimetry technique $\left(\mathrm{m}_{\text {grav }} / \mathrm{M}\right)=0.046 \pm 0.005$ applied to the original in-oil sample.

3.3 - Induced radioactivity to Dolomite. This study was carried out because in performing the tomography, the samples are irradiated in an intense neutron beam and radioactive activation of some of their chemical elements is expected $[19,20]$. In order to determine the period, after irradiation, for which the induced radioactivity becomes negligible [21], a small piece of the dry sample with mass $=0.8 \mathrm{~g}$ was powdered, and inserted in an aluminum holder. This holder was positioned in the rotating table of the NT facility and irradiated for $400 \mathrm{~s}$, the same required time to obtain the tomography [14]. The powder was analyzed in a high sensitivity Ludlum (mod. 2929 
dual scaler) counting system, which is able to detect alpha, beta and gamma radiations. The obtained result showed that approximately $24 \mathrm{~h}$ after the end of the irradiation, the counting level of the irradiated sample became insignificant, reaching the background level of the counting system.

\section{CONCLUSIONS}

The presented results demonstrate the potential of the NT technique as well as of the present NT facility to evaluate the storage capability, and distribution of oil in the reservoir mineral Dolomite, and the following conclusions can be drawn:

1 - The smallest attenuation coefficient, for the in-oil samples (Table 3), is greater than the greatest one for the dry sample, (Table 2), indicating that the oil is distributed throughout the volume of the samples and in four distinct densities. This is corroborated by the Scanning Electronic Microscope image in the Fig. 6.

2 - The greatest measured neutron attenuation coefficient for the in-oil samples was $\Sigma o\left(\mathrm{~cm}^{-1}\right)=$ 1.4 (Table 3), while the one measured for pure oil is $\Sigma o i l\left(\mathrm{~cm}^{-1}\right)=3.1$, indicating that within the sample, the oil is dispersed in densities, smaller than in its natural form.

3 - The obtained values for the oil concentration, in the three in-oil samples, agreed within their uncertainties. Furthermore, these three values have also agreed with the result obtained by the conventional gravimetry technique, demonstrating the consistency of the results and reflecting the viability of the NT to inspect the oil in Dolomite reservoir mineral, in a quantitative level.

\section{ACKNOWLEDGMENTS}

The authors thank to "Leopoldo Américo Miguez de Mello" Research and Development Center - CENPES, which has provided the Dolomite samples employed in the present work and to CAPES (Brazil) for the partial financial support to this project through the PNPD Post - Doctoral Fellowship Program. 


\section{REFERENCES}

[1] KARCH, J.; DUDÁK, J.; ŽEMLICKA, J.; VAVRÍK, D.; KUMPOVÁ, I.; KVACEK. J.; HERMANOVÁ, Z.; ŠOLTÉS, J.; VIERERBL, L.; MORGANO, M.; KAESTNER, A; TRTÍKF, P. X-ray micro-CT and neutron CT as complementary imaging tools for nondestructive 3D imaging of rare silicified fossil plants, Journal of instrumentation, 20, C12004, 2017.

[2] de BEER, F. C. Neutron and X-ray radiography/tomography: non-destructive analytical tools for the characterization of nuclear materials, The Journal of the Southern African Institute of Mining and Metallurgy, 115, 913-924, 2015.

[3] FIGUEIREDO, E; STANOJEV PEREIRA, M. A.; LOPES, F.; MARQUES, J. G.; SANTOS, J. P.; ARAÚJO, M. F.; SILVA, R. J. C.; SENNA-MARTINEZ, J. C. Investigating Early/Middle Bronze Age copper and bronze axes by micro X-ray fluorescence spectrometry and neutron imaging techniques, Spectrochimica Acta Part B, 122, 15-22, 2016.

[4] DESCHLER-ERB, E.; LEHMANN, E. H.; PERNET, L.; VONTOBEL, P.; HARTMANN, S. The complementary use of neutrons and X-rays for the non-destructive investigation of archaeological objects from Swiss collections, Archaeometry, 46, 647-661, 2004.

[5] LEHMANN, E. H.; HARTMANN, S.; SPEIDEL, M. O. Investigation of the content of ancient Tibetan metallic Buddha statues by means of neutron imaging methods, Archaeometry, 52, 416-428, 2010b.

[6] KARDJILOV, N.; FIORI, F.; GIUNTA, G.; HILGER, A.; RUSTICHELLI, F.; STROBL, M.; BANHART, J.; TRIOLO, R. Neutron tomography for archaeological investigations, Journal of Neutron Research, 14 (1), 29-36, 2006.

[7] KALOYAN, A. A.; KOVALENKO, E. S.; PAKHNEVICH, A. V.; PODURETS, K. M. The contrast scale of minerals for neutron tomography of paleontologic and geologic objects, Russian Geology and Geophysics, 58, 1435-1440, 2017.

[8] STANOJEV PEREIRA, M. A. Neutron imaging: 30 years experiencing at IPEN-CNENSP, 1th ed. Sagitarius Ed, São Paulo, ISBN 978-85-923404-1-4, 2017. 
[9] PALOMBO, L.; UlSEN, C.; ULIANA, D.; COSTA, F. R.; YAMAMOTO, M.; H. KAHN. Reservoir rock characterization by X-Ray microtomography, HOLOS, 31 (5) doi:10.15628/holos.2015.3103, 2015

[10] MILLER, J. D.; LIN, C. L. Three-dimensional analysis of particulates in mineral processing systems by cone beam X-ray microtomography, Minerals \& Metallurgical Processing, 21(3), $113-124,2004$.

[11] HARTH, W. Technical Data Sheet of the White Mineral Oil "EMCAplus 70 LF, available at http://rel.moraisdecastro.com.br:8989/smt/morais/fichatecnica.php?id_ficha=471 (accessed on November 20th, 2019).

[12] Octopus, Manual Octopus 8.6, available at https://www.octopus.be/nl (accessed on November 20th, 2019).

[13] Volume Graphics, Manual VGStudio Max 2.2, available at https://www. volumegraphics.com/ (accessed on November 20th, 2019).

[14] SCHOUERI, R. M.; DOMIENIKAN, C.; TOLEDO, F.; ANDRADE, M. L. G.; STANOJEV PEREIRA, M. A.; PUGLIESI, R., The new facility for neutron tomography of IPEN$\mathrm{CNEN/SP}$ and its potential to investigate hydrogenous substances, Applied Radiation and Isotopes, 84, 22-26, 2014.

[15] MUÑOZ, E. R. Study of carbonate wettability alteration with water and $\mathbf{C O}_{2}$ injection. (Ph.D. Thesis), University of Campinas, Brazil, 2015.

[16] CURTISS, L. F. Introduction to Neutron Physics, Boston Technical Publishers, Inc., Massachusetts, 1965.

[17] OLIVEIRA, G. J. R.; OLIVEIRA, P. C.; SURMAS, R.; FERREIRA, L. P.; MARKÖTTER, H.; KARDJILOV, N.; MANKE, I.; MONTORO, L. A.; ISAAC, A. Probing the 3D molecular and mineralogical heterogeneity in oil reservoir rocks at the pore scale, Sci Rep 98263 (2019) doi:10.1038/s41598-019-44763-6.

[18] BEERS, Y. Introduction to the Theory of Error. Physics Today 7, 3, 22 (1954); https://doi.org/10.1063/1.3061547

[19] STANOJEV PEREIRA, M. A.; PUGLIESI, R. Penetration of the consolidant Paraloid®B-72 in Macuxi indigenous ceramic vessels investigated by neutron tomography, Nucl. Instrum. Methods Phys. Res. Sect. A. Accel. Spectrom. Detect. Assoc. Equip. 889, 118-121, 2018. 
[20] PUGLIESI, R.; STANOJEV PEREIRA, M. A.; ANDRADE, M. L. G.; BASSO, J. M. L.; VOLTANI, C. G.; GONZALES, I. C. Study of the fish fossil Notelops brama from AraripeBasin Brazil by Neutron Tomography, Nucl. Instrum. Methods Phys. Res. Sect. A. Accel. Spectrom. Detect. Assoc. Equip. 919, 68-72, 2019.

[21] Nuclear Energy National Commission, available at http://appasp.cnen.gov.br/seguranca/normas/pdf/Nrm301.pdf (accessed on November 20th, 2019). 